\title{
A EDUCAÇÃO AMBIENTAL NO ÂMBITO ESCOLAR
}

Jennifer Nogueira Leite - jennifernogueira97@ gmail.com

Instituto Federal de Educação, Ciência e Tecnologia da Bahia - IFBA

Deise Danielle Neves Dias Piau - deisepiau@gmail.com

Instituto Federal de Educação, Ciência e Tecnologia da Bahia - IFBA 


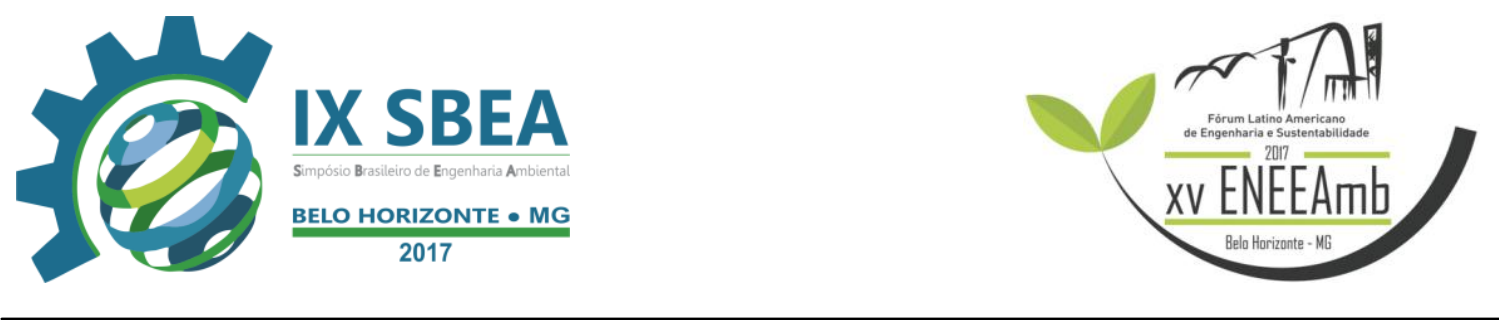

\section{RESUMO}

O ensino de educação ambiental no âmbito escolar impacta positivamente na formação de jovens e adultos. Contribui com o desenvolvimento sustentável e com a responsabilidade socioambiental, o que resulta na consciência de que o meio em que vivem é um sistema fechado e finito e por isso deve ser preservado. Este artigo tem como objetivo analisar o impacto do ensino de educação ambiental na responsabilidade socioambiental dos indivíduos uma vez que, educar é praticar educação orientada para a sustentabilidade e para contribuir com o desenvolvimento sustentável. A pesquisa é uma pesquisa de campo, descritiva e exploratória, com população específica: estudantes do ensino integrado, de um Instituto Federal, com caráter comparativo entre os estudantes de dois cursos, $4^{\circ}$ ano e $1^{\circ}$ ano, cursos integrados em meio ambiente e eletrônica. Foi verificado após a aplicação de questionários que os estudantes que possuíram o ensino de educação ambiental após um período possuem maior consciência ambiental do que os alunos que não tiveram este ensino, assim, tornou-se visível a importância da educação ambiental no âmbito escolar.

Palavras-chave: Educação Ambiental, Âmbito Escolar, Responsabilidade Socioambiental.

\section{INTRODUÇÃO/OBJETIVO}

Em tempos de globalização, a população compreende a importância e a necessidade de proteger e cuidar do planeta e do meio ambiente. Durante muito tempo a sociedade realizou o uso inadequado dos recursos naturais contribuindo para o seu esgotamento sem pensar e sem planejar a reutilização desses bens finitos. De acordo Sardinha (2000), "Hoje em dia, virou uma necessidade se adequar aos novos paradigmas do meio ambiente. O meio prejudica a qualidade de vida do homem, então a gente tem de cuidar desse meio".

O início da consciência ambiental fez com que exista uma maior preocupação com o planeta e consequentemente uma maior necessidade de educar as pessoas para adotarem atitudes socioambientais e posturas que visam o bem comum. Segundo o Ministério do Meio Ambiente (MMA), a Lei no 9795/1999, Art 1 relata que entende-se por educação ambiental os processos por meio dos quais o indivíduo e a coletividade constroem valores sociais, conhecimentos, habilidades, atitudes e competências voltadas para a conservação do meio ambiente, bem de uso comum do povo, essencial à sadia qualidade de vida e sua sustentabilidade.

O conceito de educação ambiental tem sido associado ao meio ambiente e ao modo como este está sendo conduzido e construído. No âmbito internacional, as primeiras preocupações com a educação ambiental surgiram na década de 70 . De acordo o Ministério da Educação (MEC), em outubro de 1977 houve a Conferência Intergovernamental de educação ambiental de Tbilisi, capital da Geórgia. Sua organização ocorreu a partir de uma união entre a Organização das Nações Unidas para a Educação, a Ciência e a Cultura (UNESCO) e o Programa das Nações Unidas para o Meio Ambiente (PNUMA). Segundo a UNESCO (1987) "a educação ambiental é um processo permanente no qual os indivíduos e a comunidade tomam consciência do seu 


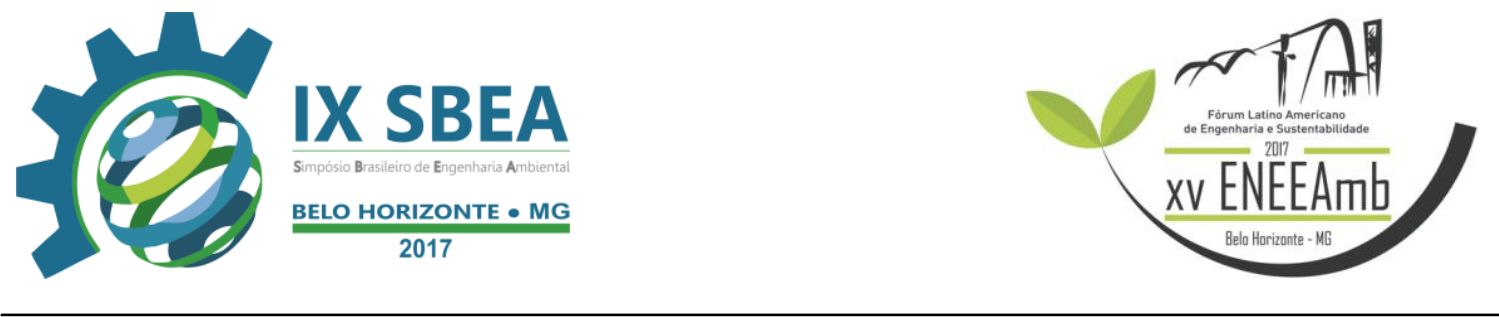

meio ambiente e adquirem conhecimentos, habilidades, experiências, valores e a determinação que os tornam capazes de agir, individual ou coletivamente, na busca de soluções para os problemas ambientais, presentes e futuros". A necessidade de educar as pessoas quanto à responsabilidade socioambiental é fundamental para construir a base para o desenvolvimento sustentável.

O objetivo deste artigo é demonstrar a importância da educação ambiental no âmbito escolar por meio de um questionário aplicado com o corpo docente de modo a analisar o impacto do ensino para a formação dos cidadãos. De acordo o MEC e o Instituto Brasileiro do Meio Ambiente e dos Recursos Naturais Renováveis (IBAMA) educar é praticar uma educação orientada para a sustentabilidade e, portanto revigorar os conceitos e metodologias propostos para a educação ambiental. A implementação desta no âmbito escolar é uma ação educativa e política que contribui para a formação de cidadãos conscientes da preservação da natureza, tornando-os pessoas preocupadas com as questões ambientais que visam contribuir com o meio ambiente e com a presente e futuras gerações, seja evitando jogar um lixo na rua ou até mesmo realizando projetos com cunho socioambiental.

\section{METODOLOGIA}

$\mathrm{Na}$ primeira etapa para a construção do artigo foram realizadas pesquisas de caráter bibliográfico sobre os impactos da educação ambiental no âmbito escolar. Os dados quantitativos foram coletados a partir dos resultados da aplicação do questionário. O trabalho não se limitou a contabilização das respostas obtidas nos questionários e na busca de uma leitura de valor qualitativo dos dados realizou-se uma análise das atitudes a depender da influência socioambiental de cada docente. O conjunto das pesquisas, dos dados coletados e tabulados e do posicionamento dos estudantes com relação á conscientização com as questões ambientais permitiu uma analisar de forma mais crítica e completa da questão estudada. O âmbito escolar utilizado para realizar a pesquisa e aplicar o questionário foi o Instituto Federal de Educação, Ciência e Tecnologia da Bahia (IFBA). O foco da pesquisa foram estudantes do instituto da modalidade integrada do primeiro ano do curso de eletrônica e estudantes do quarto ano do curso de meio ambiente.

\section{RESULTADOS E DISCUSSÃO}

A pesquisa foi realizada com discentes para comparar as atitudes e visões entre cidadãos que não possuem contato com medidas socioeducativas com as questões ambientais (G1) e com pessoas que estudam nesta área por alguns anos (G2). O questionário aplicado consta nove questões objetivas com foco na conscientização e uma pergunta sobre o que a pessoa que está respondendo o questionário realiza que acredita prejudicar o meio ambiente. As questões objetivas possuem alternativas com três possíveis respostas, sendo elas sim, não e às vezes. A questão discursiva deve ser respondida em até linhas. O questionário foi aplicado com 20 pessoas do grupo G1 e com 20 pessoas do grupo G2, totalizando 40 entrevistados.

O objetivo do questionário é analisar através de pequenas ações a consciência ambiental de pessoas que foram educadas sobre a importância da preservação do meio ambiente e de pessoas que não obtiveram este conhecimento no campo educacional para 


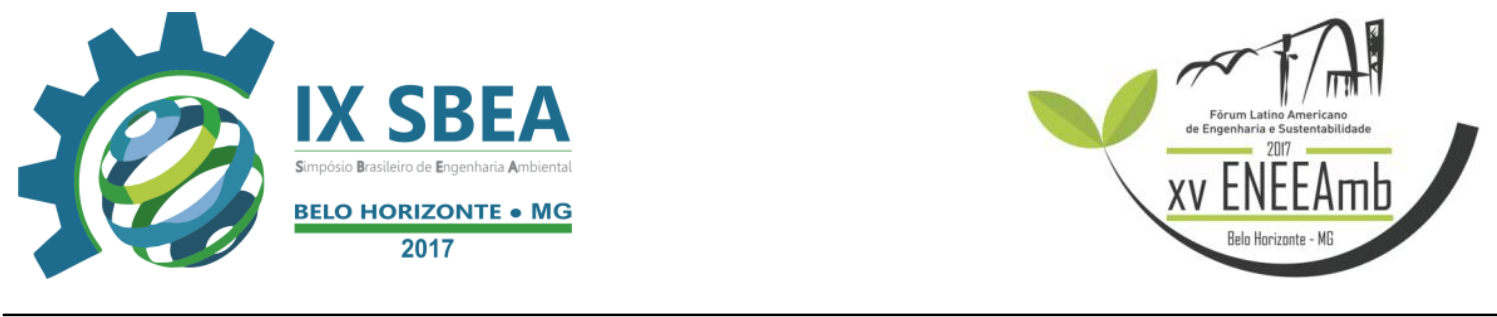

demonstrar os impactos e a importância do ensino de educação ambiental nas escolas. Para isso, as questões serão perguntas voltadas para ações simples do cotidiano, como evitar jogar um papel de bala no chão ou até mesmo ao encontrar um copo descartável no chão se o joga no lixo.

Segue abaixo os gráficos com a relação dos resultados das perguntas objetivas e a quantidade de alunos do grupo G1 (MA) e G2 (ELET) que votaram em cada uma das opções do questionário aplicado nas duas turmas.

\section{Gráfico 1: Comportamento com resíduos sólidos/Ônibus}

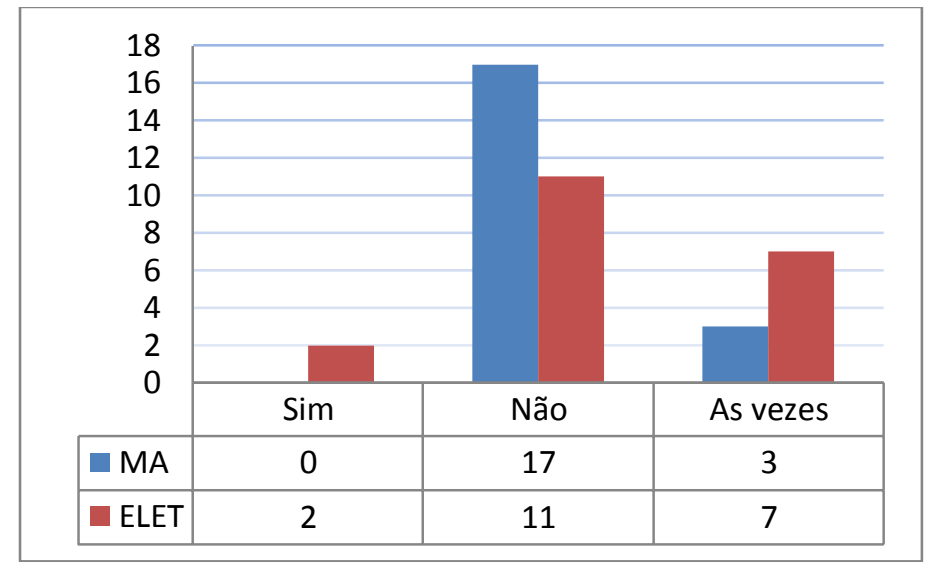

Ao identificar o comportamento dos estudantes, com os resíduos sólidos que levam consigo, durante um percurso, no interior de um veículo, foi verificado que dentre os 20 estudantes do curso de meio ambiente, $85 \%$ afirmaram guardar as embalagens de alimentos para não jogá-los em locais inapropriados e nenhum estudante relatou jogar os resíduos em locais indevidos, enquanto no curso de eletrônica, apenas $55 \%$ alunos não jogam os resíduos nas ruas e estradas e $10 \%$ informou não se importar com esta ação (Gráfico 1). No G1 apenas 15\% relatou às vezes, enquanto no G2 35\% dos alunos demonstraram o mesmo resultado.

Gráfico 2: Descuido com o desperdício de água em locais públicos

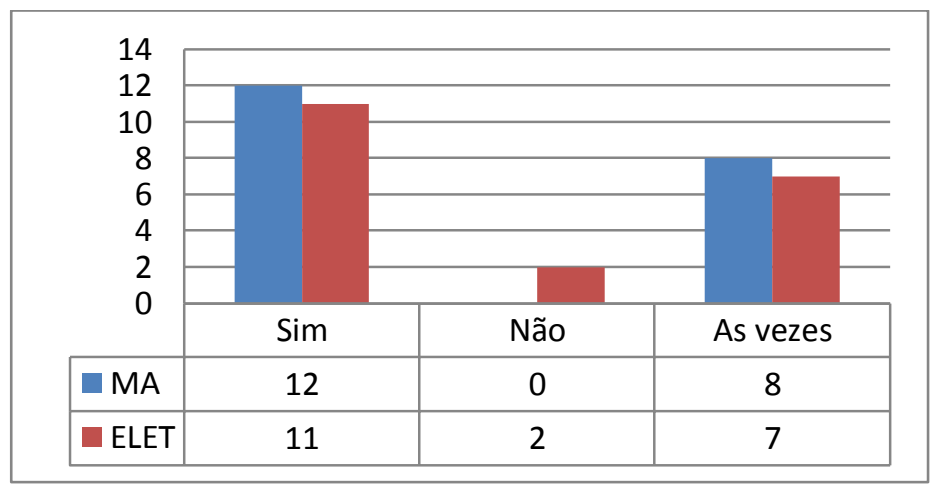

Ao analisar com 40 estudantes o descuido com o desperdício de água que ocorre em espaços públicos, $60 \%$ dos alunos do curso de meio ambiente afirmaram 


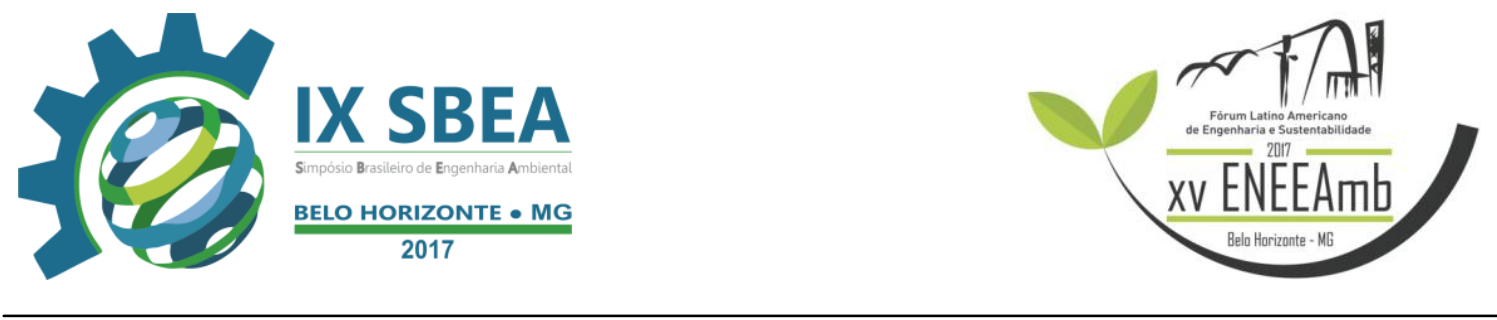

fechar as torneiras e 55\% dos estudantes de eletrônica. Não houve alunos do G1 que optaram por permitir o desperdício, enquanto $10 \%$ dos estudantes do G2 admitiram não se importar, $35 \%$ disse que às vezes fecha as torneiras e de MA $40 \%$ optou por às vezes (Gráfico 2).

Gráfico 3: Comportamento com meios de carregamento/Mercado

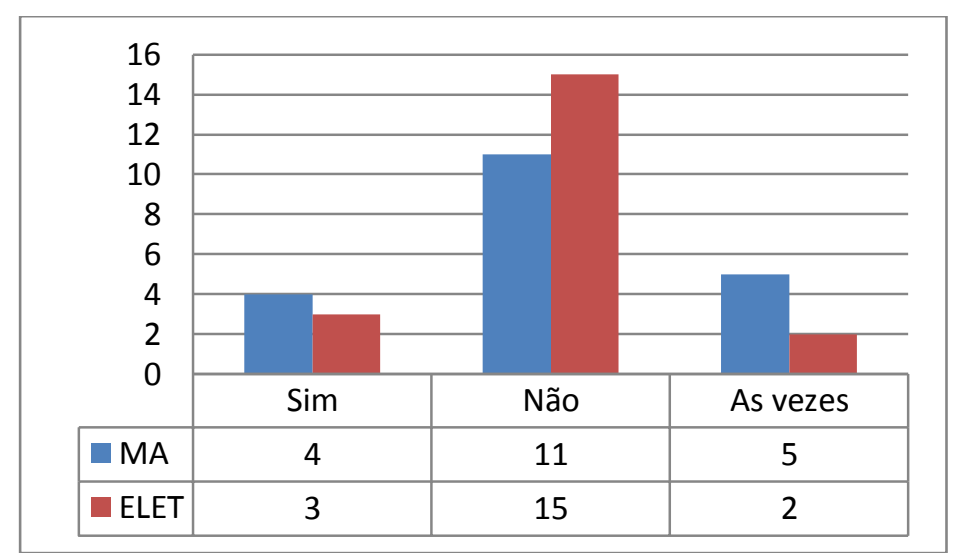

Ao observar o comportamento dos estudantes com os meios de carregar compras foi, ambas as turmas poucas pessoas já pensaram em levar ou levaram sacola ecológica ou de pano para ir ao mercado, em MA apenas 20\% dos alunos e em ELET apenas $15 \%$. Todavia, $25 \%$ das pessoas de meio ambiente pensaram em aderir esta ação enquanto em eletrônica apenas 10\% das pessoas (Gráfico 3). Que não pensaram a respeito foi $55 \%$ dos estudantes do G1 e $75 \%$ do G2.

Gráfico 4: Comportamento sobre a utilização de garrafas de água

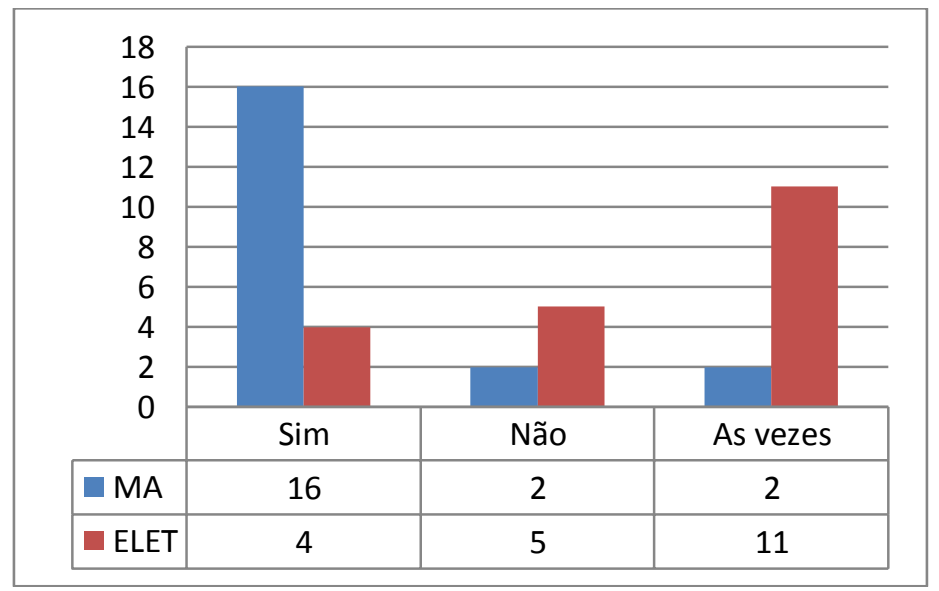

Ao analisar a utilização de garrafas de água para evitar o uso de copo descartável a todo o momento, do G1, $80 \%$ dos estudantes afirmaram utilizar com frequência, $10 \%$ apenas às vezes e $10 \%$ não fazem uso (Gráfico 4). No G2, apenas $20 \%$ dos alunos utilizam, $55 \%$ às vezes e $25 \%$ não fazem uso. 


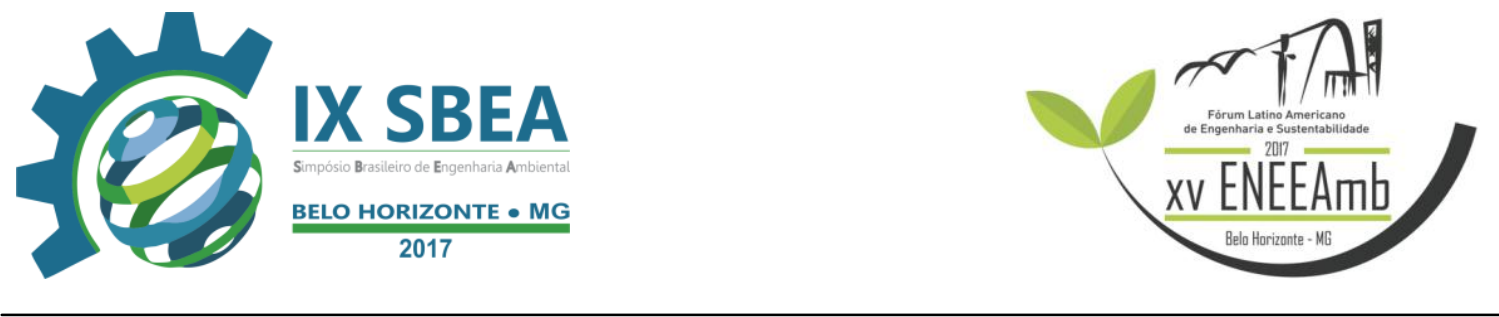

Gráfico 5: Comportamento de coleta seletiva

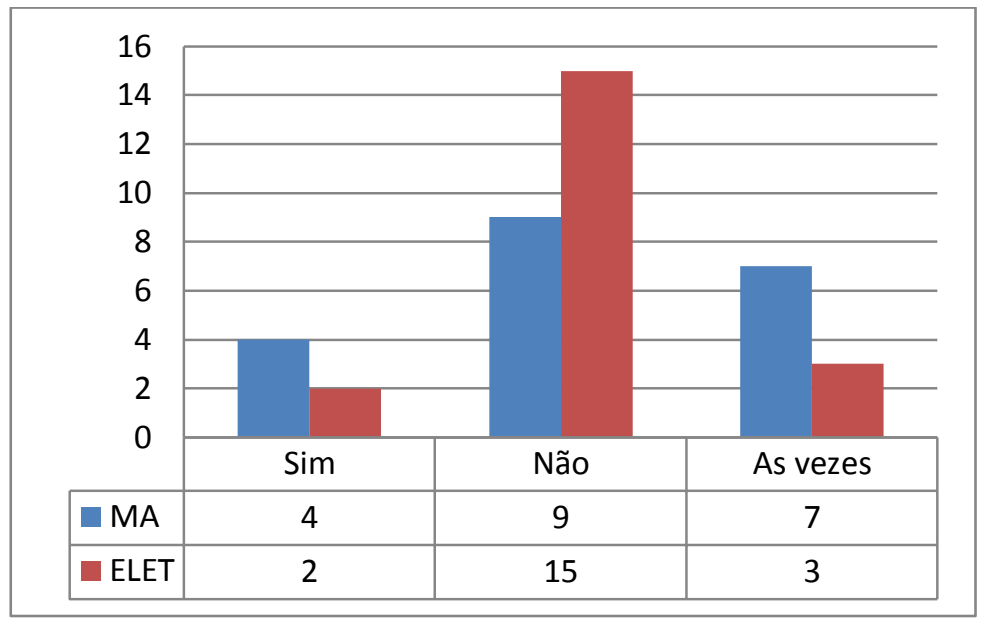

Ao verificar a quantidade de estudantes que realizam a coleta seletiva, foi observado que do G1, 20\% dos estudantes afirmaram realizar a coleta seletiva, $45 \%$ disseram não realizar e $35 \%$ concretizam às vezes. No G2, somente $10 \%$ dos alunos disseram realizar a separação dos resíduos recicláveis, $75 \%$ afirmou não fazer e $15 \%$ apenas às vezes (Gráfico 5).

Gráfico 6: Reutilização de embalagens recicláveis para criação

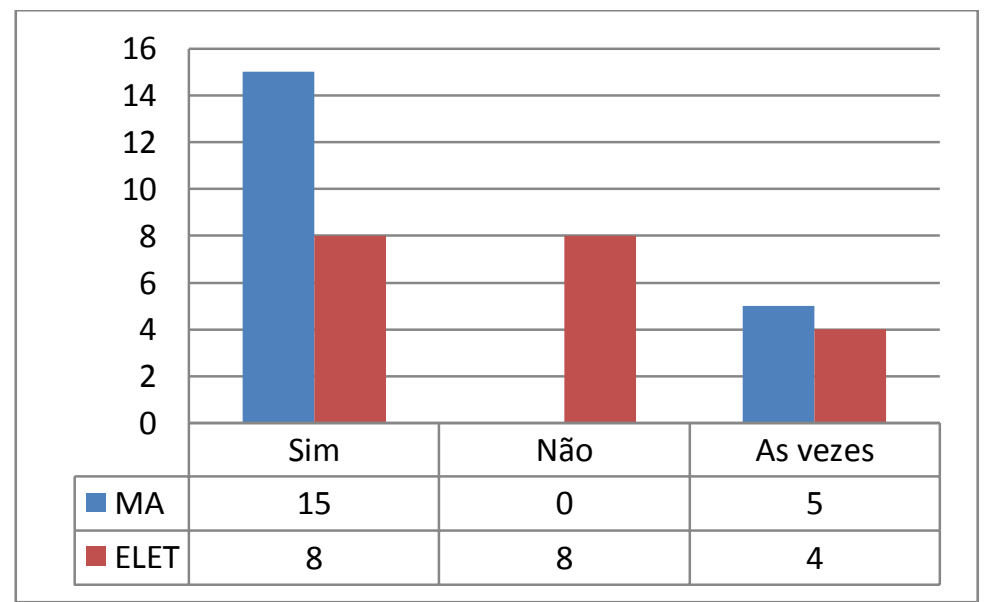

A reutilização de embalagens de produtos que poderiam ser recicladas para modificá-las de modo á atribuí-la uma utilização. Na turma de meio ambiente, $75 \%$ dos alunos responderam já ter realizado esta reutilização, apenas $25 \%$ relatou ter feito às vezes e nenhuma pessoa respondeu nunca ter reutilizado. Na turma de eletrônica, apenas $40 \%$ dos estudantes afirmaram ter realizado atividades com embalagens recicláveis, $20 \%$ disseram às vezes e $40 \%$ das pessoas relataram nunca ter realizado (Gráfico 6). 


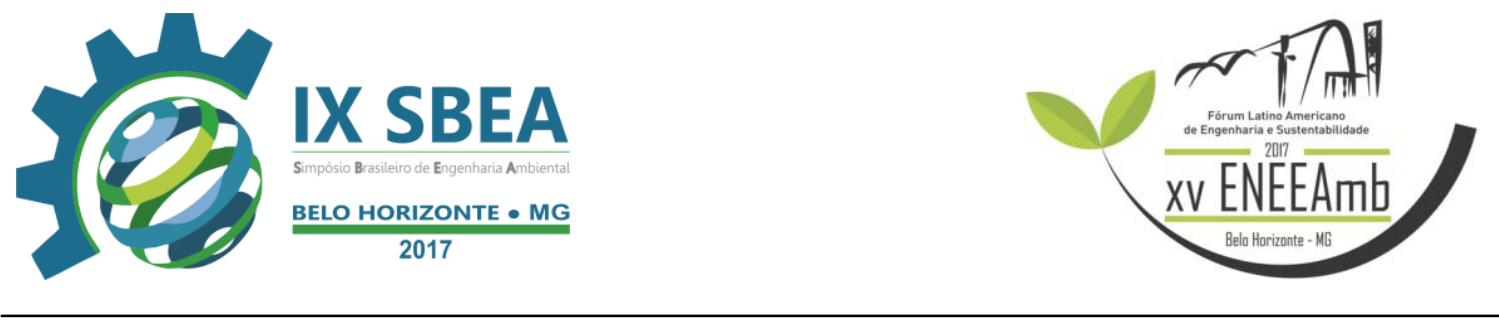

Gráfico 7: Economia de água no IFBA

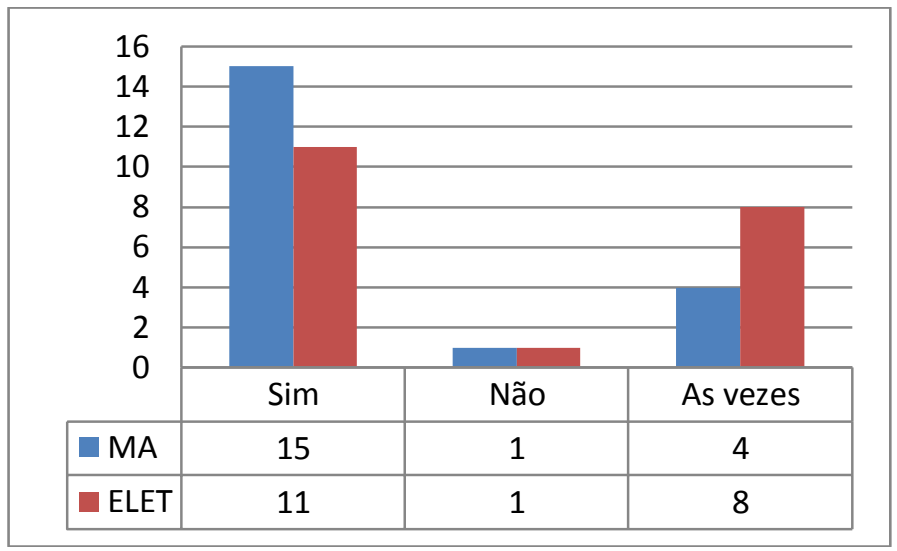

De acordo a análise do nível de preocupação em economizar água no Instituto, do G1, 75\% dos alunos da turma do quarto ano de meio ambiente afirmaram buscar economizar água no campus, enquanto $20 \%$ disseram que às vezes e $5 \%$ pessoa disse não praticar a economia (Gráfico 7). No G2, 55\% dos alunos disseram buscar meio de economizar, $40 \%$ relataram não possuir essa prática e 5\% respondeu nunca ter buscado economizar água no IFBA.

Gráfico 8: Comportamento com embalagens

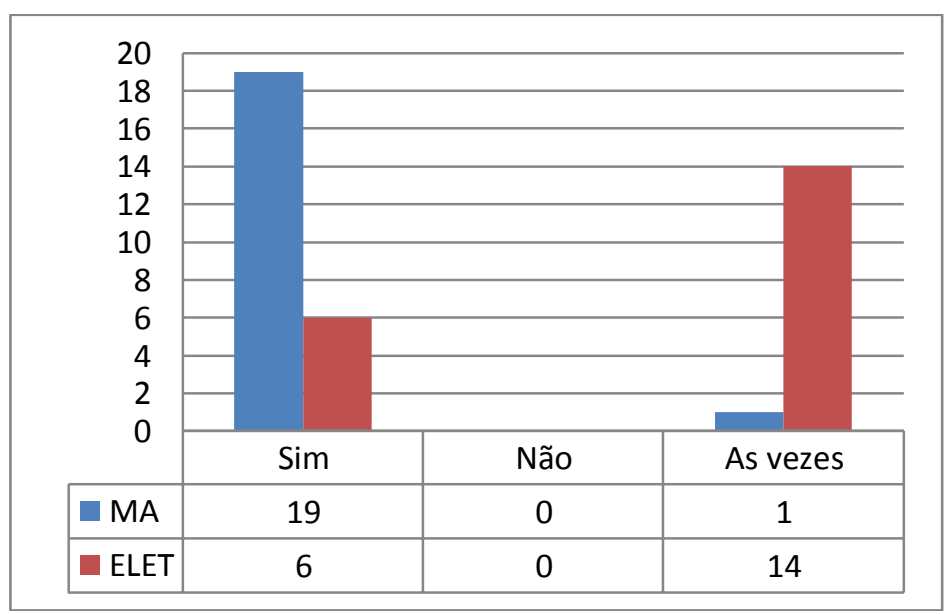

Ao analisar o comportamento com embalagens quando não possui uma lixeira por perto, na turma com a educação ambiental, 95\% dos estudantes afirmaram guardar até mesmo um papel de bala na mochila até encontrar uma lixeira e apenas $5 \%$ relatou que às vezes guarda, e às vezes descarta no meio ambiente (Gráfico 8). Na turma sem a educação ambiental, 30\% afirmou guardar na mochila e $70 \%$ dos alunos disseram às vezes. 


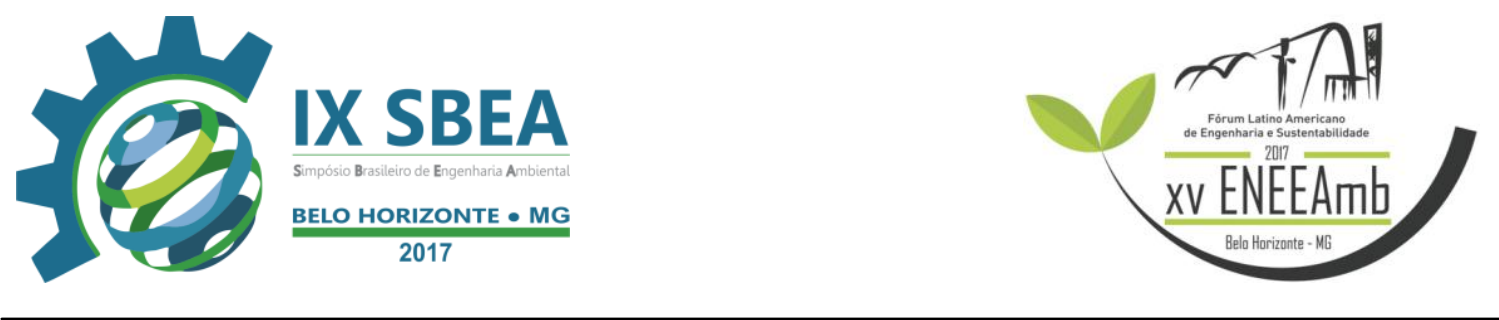

Gráfico 9: Comportamento ambiental

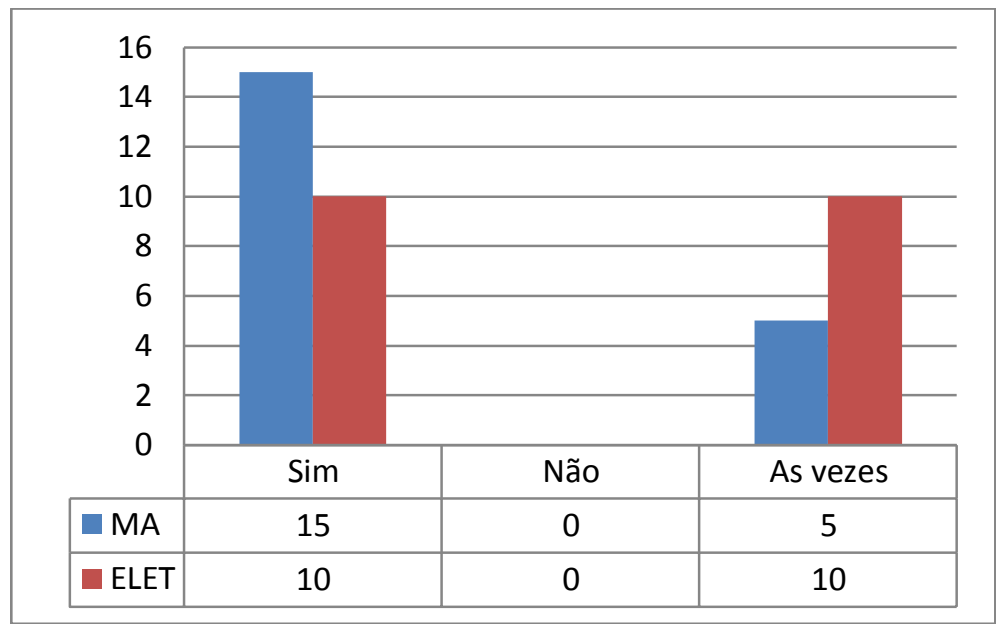

Ao observar se os estudantes se consideravam conscientes ás questões ambientais, o G1, $75 \%$ das pessoas se consideravam conscientes e $25 \%$ responderam as vezes. No G2, apenas 50\% dos alunos, metade da turma, possuía consciência das questões ambientais e os outros 50\% penas às vezes (Gráfico 9). Ou seja, $75 \%$ dos estudantes que possuem o ensino de educação ambiental são conscientes as questões ambientais e $50 \%$ dos alunos sem educação ambiental possuem consciência ambiental. A educação ambiental aumenta relativamente à quantidade de pessoas conscientes, mas não por completo.

As questões objetivas possuíram foco em questões pessoais e do cotidiano de cada indivíduo, como a preocupação em reutilizar materiais recicláveis, realizar a coleta seletiva, economizar água, levar uma garrafinha de água para evitar utilizar copo descartável ou até mesmo guardar uma embalagem de bala para quando encontrar uma lixeira. A última questão objetiva fazia os alunos refletir sobre a consciência ambiental de cada um e sobre o que ocorre no mundo em relação ao desenvolvimento sustentável.

A questão discursiva realizava o seguinte questionamento: "O que você faz para contribuir com o meio ambiente?". Entre os estudantes pesquisados, 82,5\% dos dois grupos relataram que buscam contribuir com o meio ambiente com práticas e atitudes simples, como evitar o desperdício de água e energia ou evitando despejar resíduos em locais inadequados. Dos $17,5 \%$ restantes, $10 \%$ não souberam responder ou disseram não contribuir muito e 7,5\% expuseram além das práticas do cotidiano, procuram conscientizar outras pessoas sobre a importância de prevenir e colaborar com o planeta.

A partir das respostas obtidas na aplicação dos questionários e da melhor visualização através do gráfico, é notória uma maior consciência ambiental na turma em que desfrutou do ensino de educação ambiental por quatro anos dentro do IFBA. Todavia, $25 \%$ dos estudantes não se consideram totalmente conscientes as questões ambientais e a necessidade de zelar pelo meio ambiente como meio de buscar a sustentabilidade.

O resultado da turma que não possui o ensino com foco sustentável permitiu perceber a necessidade da educação ambiental no âmbito escolar. No grupo G2, 50\% dos alunos que responderam o questionário não se consideram totalmente consciente 


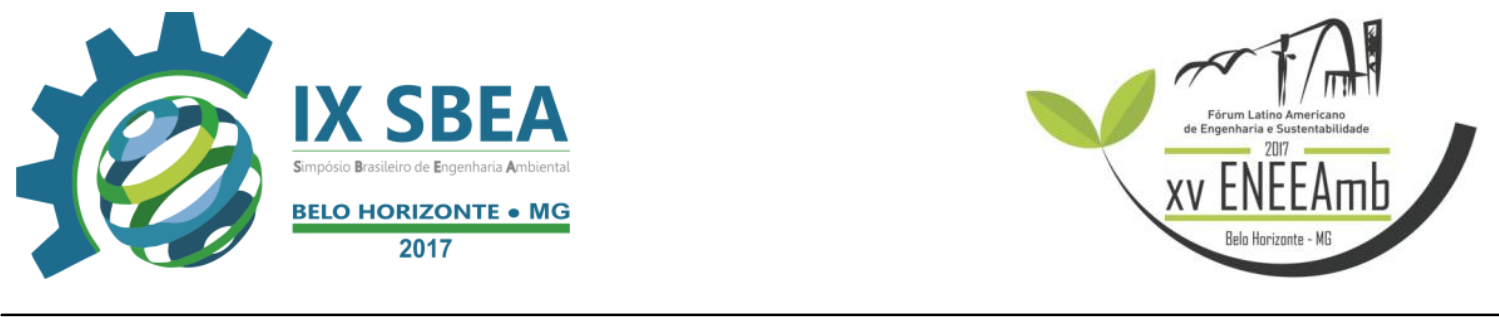

com as questões ambientais, isto demonstra que a ausência de incentivo de implantar no campo educacional a educação ambiental influencia diretamente na formação do caráter socioambiental dos cidadãos. Com isso, é possível analisar e perceber que pequenas atitudes tornam-se grandes quando trabalhadas em coletivo. Ao se responsabilizarem em jogar um simples papel de bala no lugar adequado, além de visar o bem comum ao contribuir com o meio ambiente, melhora a qualidade de vida dos seres, uma vez que a crise ambiental à degradação da qualidade de vida humana.

De acordo Layrargues (2002), o que une novas perspectivas da educação ambiental que diametralmente rompem com o modelo convencional, é a hipótese de que só será possível proteger a natureza se, ao mesmo tempo, se transformar a sociedade, pois apenas reformá-la não seria o suficiente. Ou seja, a consciência ambiental não é tudo, é necessário atitude.

Leff (2001) expõe sobre a impossibilidade de resolver os crescentes e complexos problemas ambientais e reverter suas causas sem que ocorra uma mudança radical nos sistemas de conhecimentos, dos valores e dos comportamentos gerados pela dinâmica de racionalidade existente, fundada no aspecto econômico do desenvolvimento. Isto retoma a reflexão sobre os desafios para adequar os pensamentos e ações em torno da questão ambiental.

Segundo a Constituição Federal (1988), o Estado possui o dever de "promover a Educação Ambiental em todos os níveis de ensino e a conscientização pública para a preservação do meio ambiente" (art. 225, inciso VI). Além disso, a Lei no 9.795, de 27/04/99 da Política Nacional de Educação Ambiental (PNEA) veio reforçar e qualificar o direito de todos à Educação Ambiental, indicando seus princípios e objetivos, os atores e instâncias responsáveis por sua implementação, nos âmbitos formal e informal, e as suas principais linhas de ação.

\section{CONCLUSÕES/RECOMENDAÇÕES}

O aumento dos problemas ambientais e a necessidade de desenvolvimento sustentável é resultado da falta de consciência ambiental das pessoas. É preciso investir e incentivar a educação ambiental no âmbito escolar de modo a demonstrar que além de consciência, é necessária atitude. A educação ambiental é um processo político dinâmico em permanente construção, logo, possui valores baseados na transformação social. O futuro deve ser planejado de forma socioambientalmente sustentável para que um dia as ações humanas não impactem o meio ambiente de modo a prejudicá-lo, e sim como uma construção simultânea e coletiva de sustentabilidade ambiental, política, social, econômica, e ética.

\section{REFERÊNCIAS BIBLIOGRÁFICAS}

BARCELOS, V. Educação Ambiental: Sobre princípios, metodologias e atitudes. Petrópolis: Editora Vozes. 2010.

JACOBI, P. Educação Ambiental, Cidadania e Sustentabilidade. Cadernos de Pesquisa no 118. São Paulo, Mar. 2003. p. 190-193. 


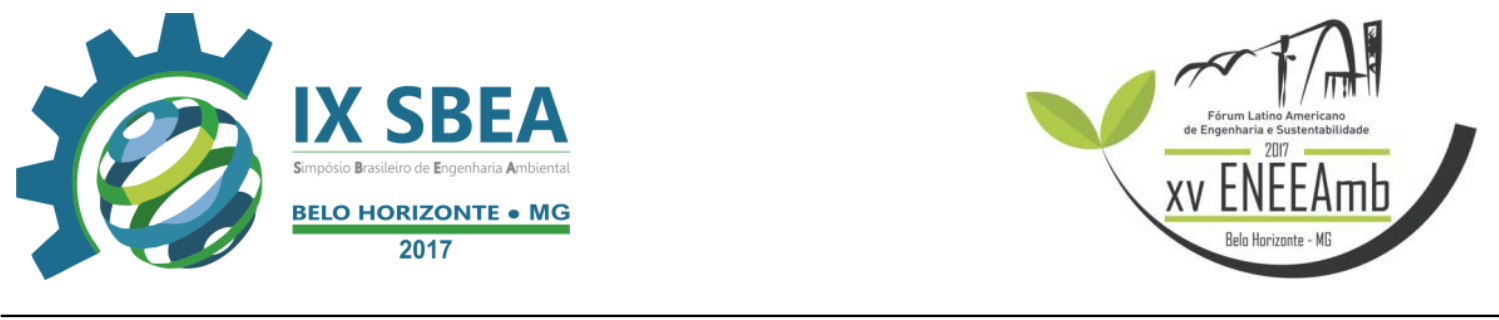

LIMA, G.C. O discurso da sustentabilidade e suas implicações para a educação. Disponível em: http://www.scielo.br/scielo.php?script=sci_arttext\&pid=S1414753X2003000300007. Acesso em: 18 mai. 2017.

MEC. Educação Ambiental: aprendizes de sustentabilidade. Brasília, Mar. 2007.

MMA, Conceitos de Educação Ambiental. Disponível em: http://www.mma.gov.br/educacao-ambiental/politica-de-educacao-ambiental. Acesso em: 18 mai. 2017.

MMA. Educação Ambiental: Curso básico a distância. Brasília: 2001.

MMA. Encontros e Caminhos: Formação de educadoras(es) ambientais e coletivos educacionais. Brasília: 2005. 